\title{
On human culture and the motive for protecting the environment
}

\author{
Tam-Tri Le \\ Centre for Interdisciplinary Social Research \\ Phenikaa University, Hanoi, Vietnam
}

2 January 2022

A person desires to protect something for its perceived value in relation to oneself (arguably, either directly as personal benefits or indirectly as altruistic purposes). The act of protecting here holds the value of prolonging the existence of that something.

In human culture, protecting oneself and loved ones, in general, is considered natural. The decision is so natural that most people take it for granted and never deeply contemplate its motives. It should be noted as well that even deciding on sustaining one's own life is a subjective cost-benefit evaluation $[1,2]$.

On this basis, we go into the "why" aspect of protecting the natural environment. Now it comes to the perceived values of nature, which are heavily individual- and context-based. Nonetheless, nobody wants to spend energy sustaining the existence of something deemed worthless (or harmful). This means that protective behaviors depend on the evaluation of nature's influences on oneself in one way or another. Here it is important to note that the subjective sphere of influence should be considered in both directions of the dynamic nature-human interaction [3].

Thus, for me and my colleagues, it is very clear that in order to create an eco-surplus culture - one that prioritizes protecting and healing nature - pro-environmental values need to be incorporated into the core of the collective mindset [4]. People will actively try to protect the environment when they perceive the action as beneficial for them (as an accepted and integrated cultural value). Now practically, we need to address the lack of consideration for cultural factors in the current state of global climate research [5].

\section{References}

1. Nguyen, M.-H., et al. (2021). Alice in Suicideland: Exploring the Suicidal Ideation Mechanism through the Sense of Connectedness and Help-Seeking Behaviors. International Journal of Environmental Research and Public Health, 18(7), 3681. https://doi.org/10.3390/ijerph18073681 
2. Vuong, Q.-H., Nguyen, M.-H., \& Le, T.-T. (2021). A Mindsponge-Based Investigation into the Psycho-Religious Mechanism Behind Suicide Attacks. Sciendo. https://doi.org/10.2478/9788366675599

3. Nguyen, M.-H. (2021). Subjective spheres of influence: A perceptual system beyond Mindsponge [Preprint]. Open Science Framework. https://doi.org/10.31219/osf.io/56jtu

4. Vuong, Q.-H. (2021). The semiconducting principle of monetary and environmental values exchange. Economics and Business Letters, 10(3), 284-290. https://doi.org/10.17811/ebl.10.3.2021.284-290

5. Vuong, Q.-H. (2021). Western monopoly of climate science is creating an eco-deficit culture. Economy, Land and Climate Insight. Retrieved from: https://elcinsight.org/western-monopoly-of-climate-science-is-creating-an-eco-deficit-culture/ 